\title{
Primary School Pupils' Perception of the Efficacy of Mother Tongue Education in Ibadan Metropolis
}

\author{
Dr. David O. Fakeye \\ Department of Teacher Education, University of Ibadan, Ibadan, Nigeria \\ E-mail: Fako4best@yahoo.com
}

\author{
Received: February 1, $2011 \quad$ Accepted: June 27, $2011 \quad$ Published: December 1, 2011 \\ doi: $10.5539 /$ ass.v7n12p72 \\ URL: http://dx.doi.org/10.5539/ass.v7n12p72
}

\begin{abstract}
This survey research investigated the perception of primary school pupils on the efficacy of MTE in enhancing cognitive achievement in selected primary schools in Ibadan metropolis. A total of 1000 pupils from 50 randomly selected primary schools were the participants in the study which attempted to provide answer to two research questions. A questionnaire was used in collecting data which were analyzed using frequency counts, percentage and t-test. Findings reveal that primary school pupils perceived MTE as good and efficacious in enhancing cognitive achievement, and there was no significant difference in male and female pupils perception of the efficacy of MTE. Based on these findings, it is recommended that MTE should further be intensified in early childhood as its benefits far outweigh its limitations.
\end{abstract}

Keywords: Mother tongue, Efficacy, Education, Perception, Primary school, Pupils

\section{Introduction}

Primary education is the most important level of education because the quality of other levels of education, secondary and tertiary is determined by its quality. That is why Adeyemi (2004) remarked that most problems manifesting at the later stages of education have their root in primary educational practices. It could be inferred from the foregoing therefore, that there is a direct relationship between the quality of primary education, which is the very foundation of an individual's educational pursuit, and the later stages of education of that individual.

Language and education are inseparable because the use of language as a medium of instruction in the teaching/learning situation goes a long way in determining the success achieved by the learner. A medium of instruction is the language used in imparting knowledge and inculcating values and norms of the society in the young ones in the formal school system.

The Nigerian National Policy on Education (NPE, 2004) stipulates that the medium of instruction in the lower primary should be the mother tongue or the language of the immediate environment and at a later stage English. Adeyemi (2004) rightly noted that for proper meaningful and purposeful educational the primary level. The mother tongue or the prevailing language of the locality should be used as the language of instruction. Also, Oyekale (2007) agreed with many other researchers by noting that the initial reading at the primary school level and adult literacy classes are best taught in the mother tongue. The outcome of the Ife Six-Year Primary Project also lends credence to the indispensable role of the mother tongue as a medium of instruction in the primary school. However, the results of Iganga experiment in Uganda, in which two classes were taught geography, one in English and the other in the mother tongue, indicated that the class taught in the English medium did better than the class taught in the mother-tongue medium. But, the use of the mother-tongue or the language of the immediate environment has been found to be of immense help in promoting childhood literacy and functional education (Osokoya, 2000). This fact has also been supported by the Rivers' Readers Project (RRP) in which a group of learners was taught in the various dialects. There was also the control group that was taught with the English medium. In the final analysis, the cost of providing initial literacy in the various dialects in limited language usage was easier and more cost effective than in the English medium. Similarly, the Iloilo experiment in Senegal also confirmed the superiority of starting off learning with the mother tongue. At the end of the experiment, which lasted two years, the local Senegalese vernacular. Higaynon, was found to be much more effective in the first two primary grades than English or French (Bamgbose, 1976). This view was also supported 
by an experiment among Ghanaian children where primary school, children had a higher vocabulary in the mother tongue than in English (Olaoye, 2007).

There are dissenting views, however, among scholars as to the efficacy of MTE. Oyekale (2007) favoured the adoption of the language of the immediate community or indigenous languages in the teaching/learning situation in the classroom. He premised his argument on the fact that the indigenous language is used to pass information and culture from one generation to another. In the same view, Osokoya (2000) reported that indigenous languages had been in use for several years in traditional education before the advent of colonialism and western education and so should continue to be used as a medium of instruction in schools hinged their arguments on the fact that the curriculum content language, apart from English, could ensure its smooth transmission to the learners (Olaoye, 2007). Arguing further in favour of English medium, Adeyemi (2004) is of the view that the English language has a considerable natural and international coverage of users with a sufficiently reliable codified form.

In Nigeria, a majority of public primary school pupils come from homes where English is not used at all in communication (Olaoye, 2007). First, a majority of children, especially in rural areas, never go to pre-primary schools. They simply begin their education at the primary school level. Children who go to pre-primary schools who are mainly children of the wealthy and of the elite, begin with an early immersion in English. The child therefore has not attained a sufficient level of proficiency in the English language to enable him/her learn the subject effectively. In the view of Olaoye (2007), an average public primary school pupil in the formal education situation has two major problems to grapple with viz: the difficulty of earning the curriculum content and secondly, coping with the medium of instruction through which the curriculum content is transmitted by the teacher. Little wonder therefore that the use of English as a medium has inhibited effective learning by the Nigerian public primary school pupils. The pupils in primary schools in Ogun State of Nigeria are no exception.

In fact, as found by Ala (1983), some multi-lingual states have introduced, a state, policy bilingual education in which the Mother tongue or a group of mother tongues in a region or a country will be used as a partial medium of instruction, combined with English. Such states argue that the policy would faster national identity, cultural awareness as well as provide solution to the aspiration of minority groups.

A cursory look at Malawi Educational scene as reported by Kamwendo (2001) also reveals a general apathy on the part of Malawian parents towards mother tongue instruction. In 1996, the secretary of Education in Malawi issued a directive that primary 1-4 should be taught through the mother tongue. However, reactions to this announcement were negative as critics expressed the fear that it would lead to a further deterioration of the already declining standards of English as if English and education were synonymous. This made them to opt for sending their children to private schools where English is the sole medium of instruction. In Botswana, Kamwendo and Mooko (2006) also report that no definite decision on the use of mother tongue instruction has been taken at Primary School Level. A Commission on Education was set up in 1993 to review Botswana education and the need to consider mother tongue instruction was highlighted in the terms of reference of the commission.

The shock which the young child undergoes in passing from the home to the school life is so great that everything possible should be done to soften it, particularly, where modern methods of infants teaching are not practiced in schools. The child passed from being one of a new child under his/her mother's care to being one of a large group under a teacher. Instead of running about, playing and shouting, the child is usually expected to sit still and be quiet, to concentrate, to do what he/she is told, instead of what he/she wants to do, to listen and learn and answer questions. New information and ideas are presented to him/her as fast as is possible. Almost everything is different from home and it is not surprising that many children have difficulty in adjusting themselves to their new surroundings. If the language in which all this bewildering new communication is made is also different from the mother tongue, the burden on the child is increased.

\section{Literature Review}

The idea that primary education is best begun in a child's MT has received a strong support in many educational and linguistic circles. A detailed analysis of research findings and published literature, however, have shown a great diversity on the basic assumptions and objectives of scholars and writers in the field. This has made it impossible to generalize such beyond the areas studied:

It is axiomatic that the best medium for teaching a child is his mother tongue. Psychologically, it is the system of meaningful signs that is in the mind works automatically for expression and understanding: sociologically, it is a means of identification among the members of the community to which he belongs. 


\section{Educationally, he learns more quickly trough it than through an unfamiliar linguistic} medium UNESCO 1953:11).

Some scholars have advocated the use of the mother tongue as a medium of instruction from the primary school level for the following reasons. One, a number of scholars (Fafunwa and Bliss, 1967: Afolayan, 1976) have written on the assumption that primary education, when given in the child's MT rather than in a second or foreign language, is more effective and meaningful. Student learning can be accurately assessed in bilingual classrooms. When students can express themselves, teachers can diagnose what has been learned, what remains to be taught and which students need further assistance. In submersion schooling cognitive learning and language learning are confounded, making it difficult for teachers to determine whether students have difficulty understanding the concept itself, the language of instruction, or the language of the test.

The affective domain, involving confidence, self-esteem and identity, is strengthened by use of the L1, increasing motivation and initiative as well as creativity. L1 classrooms allow children to be themselves and develop their personalities as well as their intellects, unlike submersion classrooms where they are forced to sit silently or repeat mechanically, leading to frustration and ultimately repetition, failure and dropout.

It was in recognition of the importance and contributions of mother tongue to education that made the Federal Ministry of Education in collaboration with other educational statutory agencies include in the National Policy on Education published in 2004, revised in 1981 the use of mother tongue as a medium of educating pupils at the pre-primary and primary level throughout the country.

According to the National Policy on education published in 2004 revised in 1981, Section 2(ii) which stated that "Government will ensure that the medium of instruction will be principally the mother tongue or the language of the immediate community" also in section $3(x x)$ of the same National Policy on Education stated that: "Government will see to it that the medium of instruction in the primary school is initially the mother tongue of the immediate community and at a later stage English".

The importance of Nigerian language in the educational process is stated in section 1 "In addition to appreciating the importance of language in educational process, and as a means of preserving people's culture, the government considers it the best interest of national unity that each child should be encouraged to learn one of the three major languages other than his mother tongue".

Several studies have shown a close relationship between the child's MT and his culture. Amao (2010) emphasized the significance of the language as the carrier and embodiment of the features of cultural environment. While Gladstone (1969) claims that language and culture are interwoven, hence, according to UNESCO (1953), the culture and the personality of the individual are reflected in his/her language. It is therefore claimed that the use of the MT for instruction will foster the cultural values of the child. Further, to Patton and Gay (1993), language, having developed in the context of a certain culture of necessity, reflects that particular culture, language, not only differentiates and integrates human interaction, but also, provides guides to behaviour and motives to conform.

A number of other writers have advocated the use of the MT as a medium of instruction and as a pre-requisite for effective learning of a second or foreign language. In the Report on African languages and English in Education, it is said that:

\section{It is quicker and more efficient for the illiterate, first to acquire literacy in the mother tongue and then to proceed to English... literacy in the mother tongue should normally be a condition of being taught English (P.29).}

While expatiating further on this, Adegbija (2004) reported that the language policy relating to primary school education in Nigeria stated that the first language is to be used in the early stages of education and English at a later stage. It is, however, vague on when this later state should occur. Consequently, most primary school teachers oscillate from the first languages to English. Understandably, this is sometimes done out of the desire to be understood and it has created problems to both the learners and the teachers.

A principal challenge to first-language medium of education policy relates to its implementation in cosmopolitan areas like Lagos, Ibadan, Port Harcourt, Kaduna and Abuja, cities in which people from many diverse ethnic groups live. Amao (2010) notes, however, that there is no reason why the first-language medium policy cannot succeed in such cosmopolitan areas because the majority of children are normally from a particular language group. Thus, such children could be taught in their first languages while special school could be established for children not catered for in the first-language medium policy, where other languages, both foreign and indigenous could serve as media of instruction. 
So far, there had been conflicting opinion, assertions and conclusions on the use of Yoruba as a medium of instruction. Bamgbose (1976), while reporting the Ife Primary Education Research Project of 1976 on the use of Yoruba as a medium of instruction, said that there was no statistically significant difference between the performance of children taught in Yoruba and those taught in English in their first School Level certificate Examination in arithmetic, English, General Knowledge and Bible knowledge Conversely, the Iganga experiment conducted in Uganda in which two classes were taught Geography, one in English and the other in the mother tongue showed that those in the English class performed better than the mother tongue class.

On the other hand, other studies (Macaulay, 1982: Ala, 1983; Ande, 1990; Akinbote 1996 and Salawu, 2000) found that mother tongue was more facilitative. The results of these studies seem inconclusive as the evidence about the superiority of a foreign medium or the mother tongue has not been well established. This may e traceable to the laissez-faire disposition of educational planners to the implementation of the National Policy on Education.

The inconclusiveness about the effectiveness of the use of mother tongue creates problem for the education policy makers the teachers and even the pupils. This is because it affects policy implementation including teaching and learning outcomes. This research essentially focused on determining the effectiveness of Yoruba and English language when they are use separately ad in combination on the achievement and classroom participation of pupils in Mathematics and Social Studies.

\section{Statement of the Problem}

The worldwide clamour for use of mother tongue in the education of the primary schoolchild has led Nigeria ,like other nations of world ,to accord indigenous languages greater recognition. Consequently, various policy measures have been taken by Nigerian government to promote mother tongue education especially at primary school levels. In addition, various mother tongue education projects have been undertaken with the results pointing to the efficacy of mother tongue in enhancing better cognitive achievement among primary school pupils. However, in spite of the numerous benefits of mother tongue education, researches have revealed a general apathy on the part of the parents, especially the literate ones towards mother tongue education in the primary schools as they express the fear that it would hinder their wards effective communication in English. Thus, they place their desire to have their children communicate in English over and above their cognitive achievement. It is pertinent to find out from the pupils themselves, what their perception is about the efficacy of mother tongue education in enhancing their cognitive achievement. Therefore, this survey research investigated the perception of primary school pupils about the efficacy of MTE in enhancing cognitive achievement in selected primary schools in Ibadan metropolis.

\section{Research Questions}

The study attempted to provide answer to two research questions namely:

1. What is the perception of primary school pupils of the efficacy of mother tongue education?

2. What is the preference of primary school pupils between MT medium and English medium?

3. Will the perception of male and female primary school pupils differ significantly?

\section{Scope of the Study}

The study was delimited to primary pupils in Ibadan metropolis. It attempted to find out the perception of the pupils of the efficacy of MTE.

\section{Purpose of the Study}

The study sought to find out from the perspectives of the pupils the efficacy of MTE. Specifically, it sought to find out the efficacy of MT as a medium of instruction and the extent to which it facilitates effective teaching and learning at this important level of education.

\section{Significance of the Study}

The study would provide a landmark information form the perspective of the primary school pupils on the efficacy of Mother Tongue Education. Also, findings from the study has helped to corroborate empirical research findings and claims by scholars on the effectiveness of Mother Tongue Education.

\section{Methodology}

\subsection{Research Design}

The design adopted in this study was a survey research design. 


\subsection{Population and Sample}

The study population comprised all primary school pupils in Ibadan metropolis. There are 198 public primary schools in Ibadan metropolis out of which a total of 50 primary schools were randomly sampled. In each primary school primary five classes were purposively selected while 20 primary five pupils were randomly selected in each school. In all 1000 primary five pupils took part in the study. The average age of the respondents was 12 years.

\subsection{Research Instrument}

The instrument used for data collection was a self-designed questionnaires tagged "Primary school Pupils' Perception of Efficacy of Mother Tongue Questionnaire. The questionnaire contained 25 items carefully worded to elicit responses from the participants.

\subsection{Validation of the Instrument}

The first draft of the questionnaire was given to experts in psychological testing in the Faculty of Education, University of Ibadan to ensure its content and face validity. Thereafter, the reliability of the instrument was determined using Cronbach Alpha and a coefficient of .79 was obtained.

\subsection{Procedure for Data Collection}

The researcher visited the schools of study, sought the permission of the headmaster/headmistresses of the school, and thereafter went straight to distribute the

questionnaire to the participants with the help of their class teachers. The researcher was on hand to provide explanations, and sometimes translations of the items in Yoruba, to the pupils to ensure that the questionnaire was correctly completed. The completed questionnaire was collected on the spot.

\subsection{Method of Data Analysis}

Data colleted were analysed using descriptive statistics of frequency counts and percentage. Also, inferential statistics of t-test was used to determine if there was significant difference in the male and female pupils' perception of the efficacy of Mother Tongue Educational at 0.05 level of significance.

\section{Results}

Research Question 1: What is the Perception of Primary School Pupils on the efficacy of Mother Tongue Education?

Table 1 shows that most of the pupils perceive MTE as interesting and efficacious (75\%); providing opportunities for learners to learn easily ( $80 \%$ )and that it makes lessons learner- centred (62\%). Also $70 \%$ argued that it facilitates effective teaching and learning

and that it is easier to remember information when mother tongue is used to and that immediate feedbacks are feasible (88\%) while $79 \%$ see it as enhancing exchange of ideas among learners.

Research Question 2: What is the preference of Primary School Pupils between mother tongue medium and English Language medium in classroom instruction?

Table 2 shows that the participants would prefer MT education to the use of English. 80\% were of the view that it was hard for them to feel motivated enough to learn via English. $60 \%$ see MT medium as making learning easier. $80 \%$ prefer learning through MT medium to English medium $85 \%$ see MT medium as enhancing better learning.

Research Question 3: Is there any significant difference in the perception of male and female pupils about efficacy of mother tongue Education?

Table 3 shows that there is no significant difference in the perception of male and female pupils about efficacy of MT Education $(\mathrm{df}=998, \mathrm{t}=2.71)$.

\section{Summary of Findings}

The study investigated the perception of Primary school pupils about efficacy of mother tongue Education. Findings reveal that Pupils perceive MT education as interesting and facilitative of effective teaching and learning. Pupils also prefer the use of mother tongue in teaching to the use of English. There is no significant difference in the perception of male and female pupils on the efficacy of mother tongue Education.

The study found that pupils perceived MT education as being both positive and efficacious. Their positive view of MT education are that it is interesting and facilitative of effective teaching and learning. English medium was 
perceived as being incapable of facilitating effective teaching and learning,and giving limited opportunity for learners. These findings are akin to that of Inozu and Ilin (2007) who found that secondary school students have both positive view of the use of mother tongue in teaching social studies concepts.. The positive perception held about MTE could be explained by the fact that the effectiveness of MTE is closely linked with the peculiar conditions or circumstances in the learners locals environment.

Findings from the study also reveal that primary school pupils prefer mother tongue medium of teaching to English-medium. This is in line with the finding of Son (2007) who while investigation of learner experiences in web-based language learning reported that learners did not enjoy learning through foreign language and if given the opportunity they would opt for mother tongue medium throughout their primary education. The fact that male and female pupils did not differ significantly in their perception might be as a result of the fact that both categories of learners are influenced by the same local contextual conditions in Nigeria where English language, a foreign language is used to disseminate curriculum content which is also foreign.

\section{Conclusion}

It could be concluded from this study that pupils perceived the efficacy of mother tongue education as positive and facilitative of effective teaching and learning. They also would that mother tongue medium is extended beyond the lower levels of primary education to cover the upper levels.

\section{Recommendation}

Based on the findings in this study, it is recommended that mother tongue teachers need be explicitly trained to adopt it in the teaching of technical school subjects for effective learning. In addition, the policy provision that Mother Tongue (MT) or Language of Immediate Community (LIC) should be used for teaching and learning activities at lower level of primary education should be rigorously pursued and if possible extended to upper primary to demystify learning of core subjects of the curriculum.

\section{References}

Adegbija O.A. (2004). Language Policy and Planning in Nigeria. Current Issues in Language planning, 5(3), 181-200. http://dx.doi.org/10.1080/14664200408668258

Adeyemi, A.E. (2004). Influence of Home Background on Academics Performance of Pupils. Unpublished B.Ed Project, University of Ibadan, Ibadan.

Afolayan, A. (1976). The Six-Year Primary Project in Nigeria. In Bamgbose, A. (ed.) Mother Tongue Educational: The West African Experience. London: UNESCO, Hodder \& Stoughton Educational.

Akinbote, O. (1996). Parents' Characteristics and Attitudes Towards the Use of Mother-Tongue as a Medium of Instruction in Primary Education. The Beagle 1, (1 \& 2), 40-45.

Ala, F..O. (1983). effects of Alternative language Media on the learning of Family Living Among Primary Five Pupils. Unpublished Ph. D Thesis, University of Reading, England.

Amao, T. A. (2010). Effects of Two mediums of Instruction on Primary School Pupils Classroom Participation Academic Achievement in Osun West Senatorial District. Unpublished PhD Thesis University of Ibadan, Nigeria.

Ande, I.I. (1990). Effects of Language of Instruction on the Learning of conservation of Weight and Continuous Quantity by Primary Two Pupils. Unpublished Ph.D Thesis, Department of teacher Education, University of Ibadan.

Bamgbose, A. (1976). Mother Tongue Education: The West Africa Experience. London: Holder and Stoughton Educational.

Crawford, L. (2000). Curricular Alternatives for second language learnin. HIGGS, 10(2), 61-72.

Fafunwa, A.B. and Bliss, R. (1967). Effect of Bilingualism on the Abstract and Concrete Ability Thinking of Yoruba Children. Monograph, University of Ife, Nigeria.

Gay, G. (1993). Building culture bridge: A bold proposal for Teacher Education. Education and Urban society, 25(3), 285-299. http://dx.doi.org/10.1177/0013124593025003006

Gladstone, J.A. (1969). Language and Culture. English language teaching, 23(2).

Kamwedo, G. \& Mooko, T. (2006). Language Planning in Botswana and Malawi: A Comparative Study. International Journal of Society and Language, 182(2), 117-133. http://dx.doi.org/10.1515/IJSL.2006.072 
Kamwendo, G.H. (2008). The Bumpy Road to Mother Tongue Instruction in Malawi. Journal of Multilingual and Multi-Culture Development, 29(50), 110-121.

Macaulay, J.I. (1982). Effects of Language of Instruction on selected Instruction Process and Outcomes. Unpublished Ph.D Thesis, University of Ibadan.

National Policy on Education. (2004). Yaba: NERDC.

Ojetola, O.O. (2008). Effects of two modes of ICT-Based strategies on sutdents' Achievement in Yourba Orthography in Ibadan Metropolis. PhD Research Proposal Department of Teacher Education. University of Ibadan.Nigeria.

Olaoye, A. (2007). Trends in the Performance of Students in Yoruba Language at SSCE Unpublished M. Ed Project, Department of Teacher Education, University of Ibadan.

Osokoya, I.O. (2000). Home Variables as Correlates of Junior Secondary School Achievement in History. African Journal of Education Planning and Policy Studies, Vol. 1(2), pp. 12-19.

Oyekale, A.O. (2007). Comparative Analysis of Performance of Students in Yoruba at Senior Secondary Certificate Examination in Lagelu Local Government of Oyo State. Unpublished M.Ed Project. University of Ibadan, Ibadan.

Salawu, K.A. (2000). Language of Instruction and Pupils' Learning Outcomes in Selected Aspects of Primary Social Studies in Ogun State, Nigeria. Unpublished Ph.D Thesis Department of Teacher Education, University of Ibadan, Ibadan.

UNESCO, (1953). The Use of Vernacular Language in Education. Monographs of Fundamental Education vii, Paris.

Table 1. Perception of Primary School pupils on the efficacy of Mother Tongue Education

\begin{tabular}{|c|c|c|c|c|}
\hline & Agree & $\%$ & Disagree & $\%$ \\
\hline Use of mother tongue makes leaving interesting & 750 & 75 & 250 & 25 \\
\hline Mother tongue makes learning easier & 800 & 80 & 200 & 20 \\
\hline It makes for active class room participation & 850 & 85 & 150 & 15 \\
\hline It facilitates effective teaching and learning & 700 & 70 & 300 & 30 \\
\hline $\begin{array}{l}\text { It is easier to remember information obtained from the lesson taught with } \\
\text { mother tongue }\end{array}$ & 710 & 71 & 290 & 29 \\
\hline It is possible to use mother tongue to learn every subject & 600 & 60 & 400 & 40 \\
\hline It makes lesson learner centered & 620 & 62 & 380 & 38 \\
\hline Immediate feedbacks to questions is easy to get when mother tongue is used & 880 & 88 & 120 & 12 \\
\hline Sharing of ideas with classmates is easy in mother tongue & 790 & 79 & 210 & 21 \\
\hline
\end{tabular}

Table 2. Preference between MT medium and English medium

\begin{tabular}{|c|c|c|c|c|}
\hline & Agree & $\%$ & Disagree & $\%$ \\
\hline I prefer MT medium to English medium & 800 & 80 & 200 & 20 \\
\hline MT medium enhances better learning than Englsih medium & 600 & 60 & 400 & 40 \\
\hline Learning is more difficult through English medium than MT medium & 750 & 75 & 250 & 25 \\
\hline Quality of instruction is higher with MT medium than English Medium & 800 & 80 & 200 & 20 \\
\hline $\begin{array}{l}\text { There is less stress in learning with mother tongue than with English } \\
\text { language }\end{array}$ & 850 & 85 & 150 & 15 \\
\hline
\end{tabular}

Table 3. Summary of t-test showing difference in perception of male and female pupils about efficacy of Mother Tongue Education

\begin{tabular}{|l|l|l|l|l|l|l|l|}
\hline Variable & N & Mean & SD & t & Df & Sig. & Remarks \\
\cline { 1 - 6 } Male & 590 & 59 & 3.73 & & & & \\
\cline { 1 - 5 } Female & 410 & 41 & 5.12 & .271 & 998 & .787 & Not Sig. \\
\hline
\end{tabular}

*Not significant of $\mathrm{P}<.0 .5$ 